\title{
The rate of colonization by macro-invertebrates on artificial substrate samplers
}

PETER G. MEIER, DAVID L. PENROSE*, and LOREN POLAK $\dagger$ Department of Environmental and Industrial Health, The University of Michigan, Ann Arbor U.S.A.

SUMMARY. The influence of exposure time upon macro-invertebrate colonization on modified Hester-Dendy substrate samplers was investigated over a 60 -day period. The duration of exposure affected the number of individuals, taxa and community diversity.

The numbers of individuals colonizing the samplers reached a maximum after 39 days and then began to decrease, due to the emergence of adult insects. Coefficients of variation for the four replicate samples retrieved each sampling day fluctuated extensively throughout the study. No tendencies toward increasing or decreasing coefficients of variation were noted with increasing time of sampler exposure.

The number of taxa colonizing the samplers increased throughout the study period. The community diversity index was calculated for each sampling day and this function tended to increase throughout the same period. This supports the hypothesis that an exposure period of 6 weeks, as recommended by the United States Environmental Protection Agency, may not always provide adequate opportunity for a truly representative community of macro-invertebrates to colonize multiplate samplers.

Many of the taxa were collected in quite substantial proportions after periods of absence or extreme sparseness. This is attributed to the growth of periphyton and the collection of other materials that created food and new habitats suitable for the colonization of new taxa.

Investigation of the relationship between 'equitability' and length of exposure revealed that equitability did not vary like diversity with increased time of exposure.

\section{Introduction}

The multiplate artificial substrate sampler is used by water pollution investigators because

*Present Address: Department of Air and Water, State of North Carolina, Raleigh, North Carolina 27602

$\uparrow$ Present Address: Wapora, Inc., Box 29, Green Valley, Illinois 61534

Correspondence: P. G. Meier, Department of Environmental and Industrial Health, School of Public Health, The University of Michigan, Ann Arbor, Michigan 48109 of several advantages. These include its light weight, ease in handling, simplicity in construction and it provides a favourable habitat with quite uniform and reproducible substrate composition and area. This permits the collection of benthos in various types of stream bottoms (areas which may be impossible to sample by most other techniques) without vastly affecting sampling efficiency. As pointed out by Cairns \& Dickson (1971), many sampling techniques require that the operator must expend the same amount of 
effort at each station before comparisons can be made among the collected organisms. Therefore, the operator must sample the same types of substrates with the same degree of efficiency at each station. This necessitates a subjective judgement on the part of the operator; consequently, errors can result. Artificial substrates eliminate much of this subjectivity, and permit flexibility and efficiency in sampling programmes.

Multiplate samplers depend to a large extent upon chance colonization by drifting or swimming organisms. Furthermore, the attachment of periphyton and collection of detritus with increasing exposure time may greatly influence the rate of colonization and the composition of the macro-invertebrate community which develops. Consequently, as pointed out by Weber (1973), the time of exposure may be critical to the development of a truly representative community of organisms. This has led the United States Environmental Protection Agency (Weber, 1973) to provisionally recommend a 6 -week exposure period while stating that this standard is based upon inadequate data. Therefore, an investigation was carried out to provide information on the effects and influences that varying periods of exposure have on the colonization of macro-invertebrates on artificial substrate samplers.

\section{Study site description}

An area containing ideal physical and chemical characteristics suited for this study was located in a section of Fleming Creek within the confines of The University of Michigan Botanical Gardens near Ann Arbor, Michigan, U.S.A. The drainage area of $31 \mathrm{~km}^{2}$ consists primarily of pasture land mixed with some cultivated areas, and only a few dwellings.

The section of the stream utilized was a riffle area with constant velocity, depth and uniform substrate. Current velocities were determined at particular locations and depths at which the samplers were placed and ranged from 8 to $20 \mathrm{~cm} \mathrm{~s}^{-1}$. Water temperatures fluctuated from 7.5 to $20.5^{\circ} \mathrm{C}$ during the study. The stream possessed a substrate consisting of relatively uniform portions of sand, gravel and small stones. Alkalinity was
3.7-4.4 m-equiv. $1^{-1}$, and dissolved oxygen ranged from 8.5 to $10.0 \mathrm{mg} \mathrm{l}^{-1}$. Fluctuations in the various physical and chemical characteristics were not great, and did not appear to noticeably affect the colonization of organisms on the multiple samplers.

\section{Methods}

\section{Sampler description}

Hester-Dendy (1962) multiplate samplers with two modifications were used in this study. Four plates were used instead of eight in each sampler, and the samplers were anchored in the stream bottom by driving the remaining lower portion of the threaded rod into the substrate. Surface area available for colonization was $0.05 \mathrm{~m}^{2}$.

\section{Study design}

On 25 April 1974, eighty-eight modified hardboard multiplate samplers were placed on the stream bottom at the study site in eleven rows of eight samplers each. Sixtyseven of the originally exposed samplers were recovered at random, with twentyone being lost due to vandalism. In the early stage of the study, sets of four samplers were removed at 2-day intervals. After 18 days of exposure, samplers were removed at 4-day intervals, again in sets of four. With the completion of 39 days from the time of initial sampler placement, the last eleven samplers were removed at intervals of 8,7 and 6 days in sets of four, four and three samplers for the respective time periods.

\section{Sample Treatment}

The plate samplers were brought into the laboratory and the organisms were handpicked from them and preserved in $70 \%$ ethanol. Organisms from the four plates of each sampler were pooled to provide one sample. The macro-invertebrates excluding midges and worms were stored and identified at a magnification of $\times 70$.

Chironomids and oligochaetes were mounted in a few drops of polyvinyl-lactophenol on microscope slides and identified to the generic level at $\times 100$ and $\times 400$ 
magnification. Taxonomic designation was determined using several available references. Oligochaetes were identified after Brinkhurst and Jamieson (1971); Turbellaria, Pelecypoda, Gastropoda, and Acari according to Ward \& Whipple (1959); Plecoptera using Hilsenhoff (1970) and Frison (1935); Ephemeroptera by Burks (1953) and Hilsenhoff (1970; Trichoptera after Hilsenhoff (1970) and Ross (1944); Diptera using Beck \& Beck (1966), Chernovskii (1949), Johannsen (1937), Mason (1973), Roback (1957), Usinger (1956) and Wood (1963) where appropriate, and Coleoptera according to Usinger (1956) and Sinclair (1964).

The taxonomic treatment of each group was uniform throughout the study, and each particular level of identification (species, genera, etc.) was considered as one taxon in the determination of total number of taxa.

\section{Results and discussion}

Estimated means and 95\% confidence limits of macro-invertebrates on each sampling date are presented in Table 1.

The mean number of organisms taken on each sampling occasion was related to the time of exposure for up to 39 days, after which there was an apparent decrease in the total number of individuals (Fig. 1). Therefore, a linear regression line was fitted for this 39-day period and the regression coefficient of $12.7 \pm 2.48 \quad 95 \% \quad \mathrm{CL}$ was highly significant $(P<0.01)$. Hence the mean rate of increase of 12.7 individuals per day indicates the critical importance of the time of exposure in attaining a relatively abundant community of aquatic macro-invertebrates.

Figure 1 reveals that the peak in total numbers occurred with 39 days of exposure.

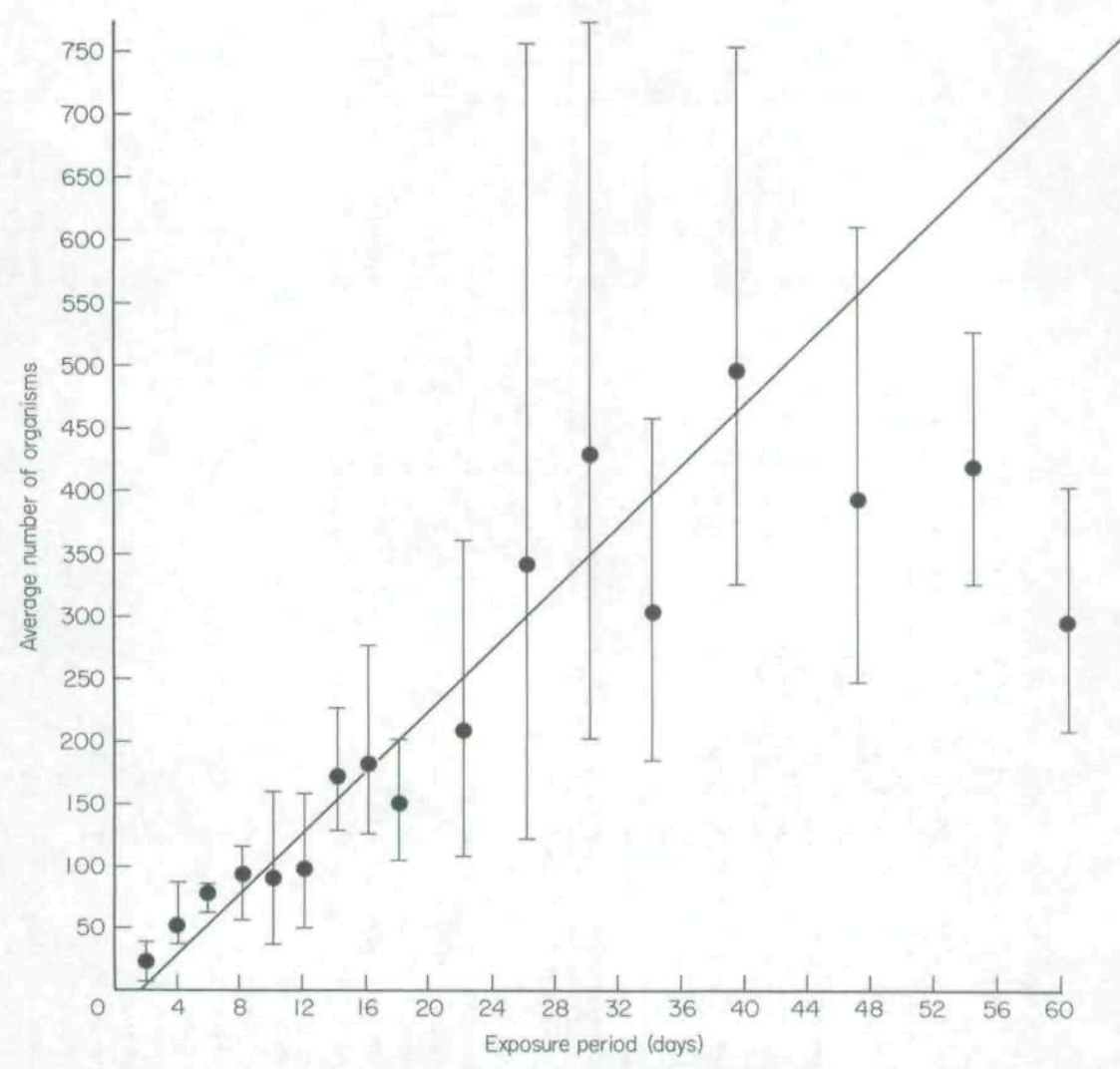

FIG. 1. Rate of accrual of macro-invertebrates over a 60-day period. The line is the regression determined from data for the first 39 days. Each point is the arithmetic mean number of organisms; the vertical bars represent $95 \%$ confidence limits for geometric means, derived from log-transformed data. 


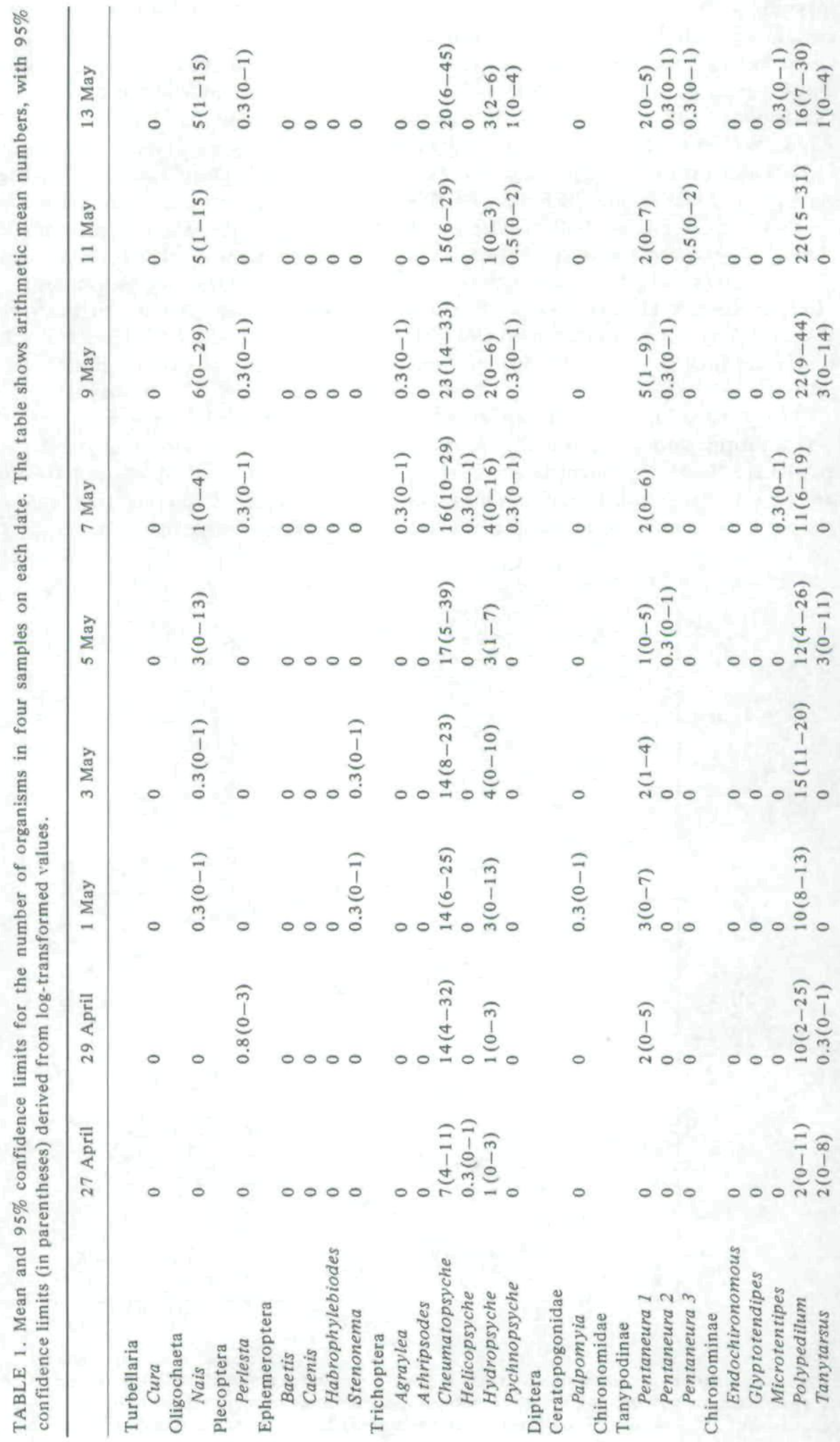




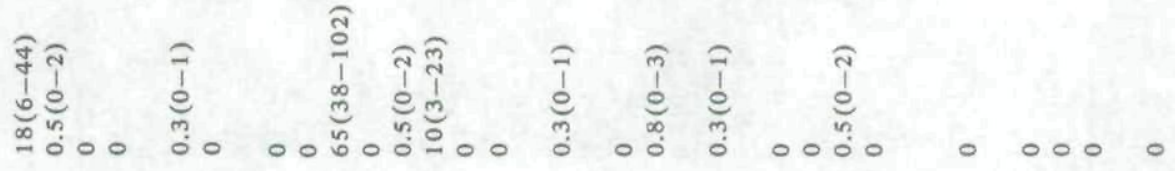

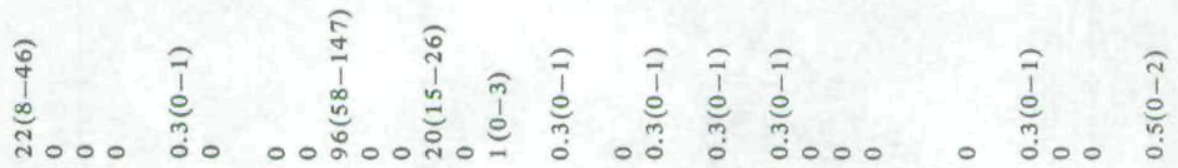

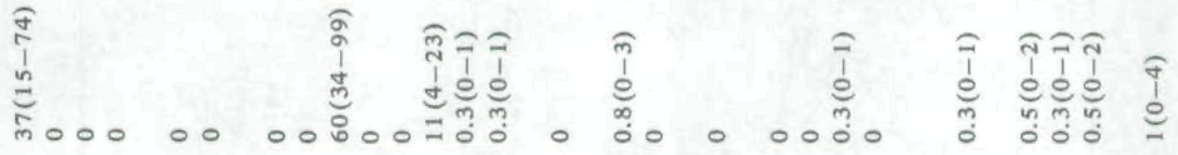

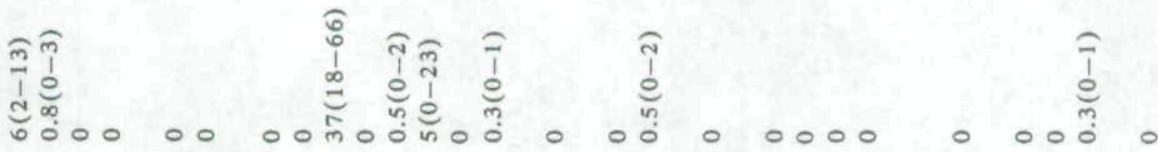

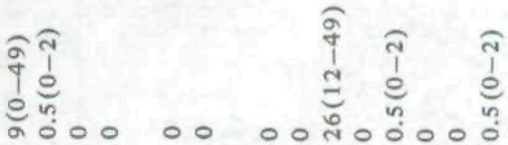

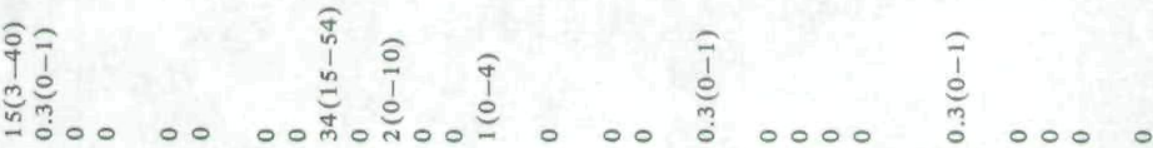

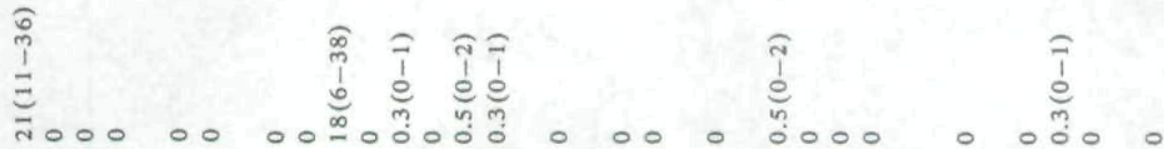

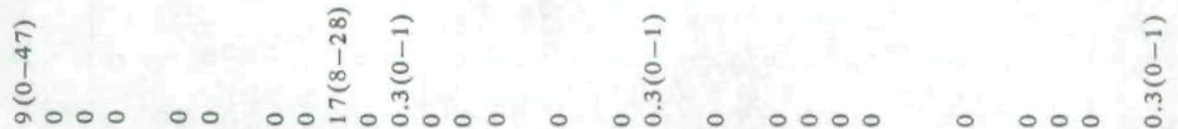

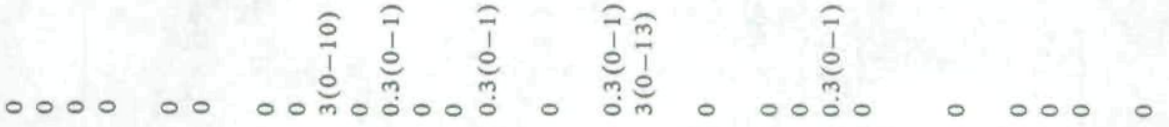

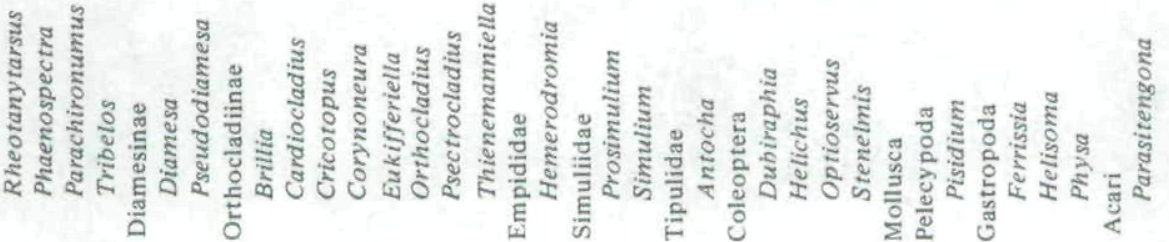




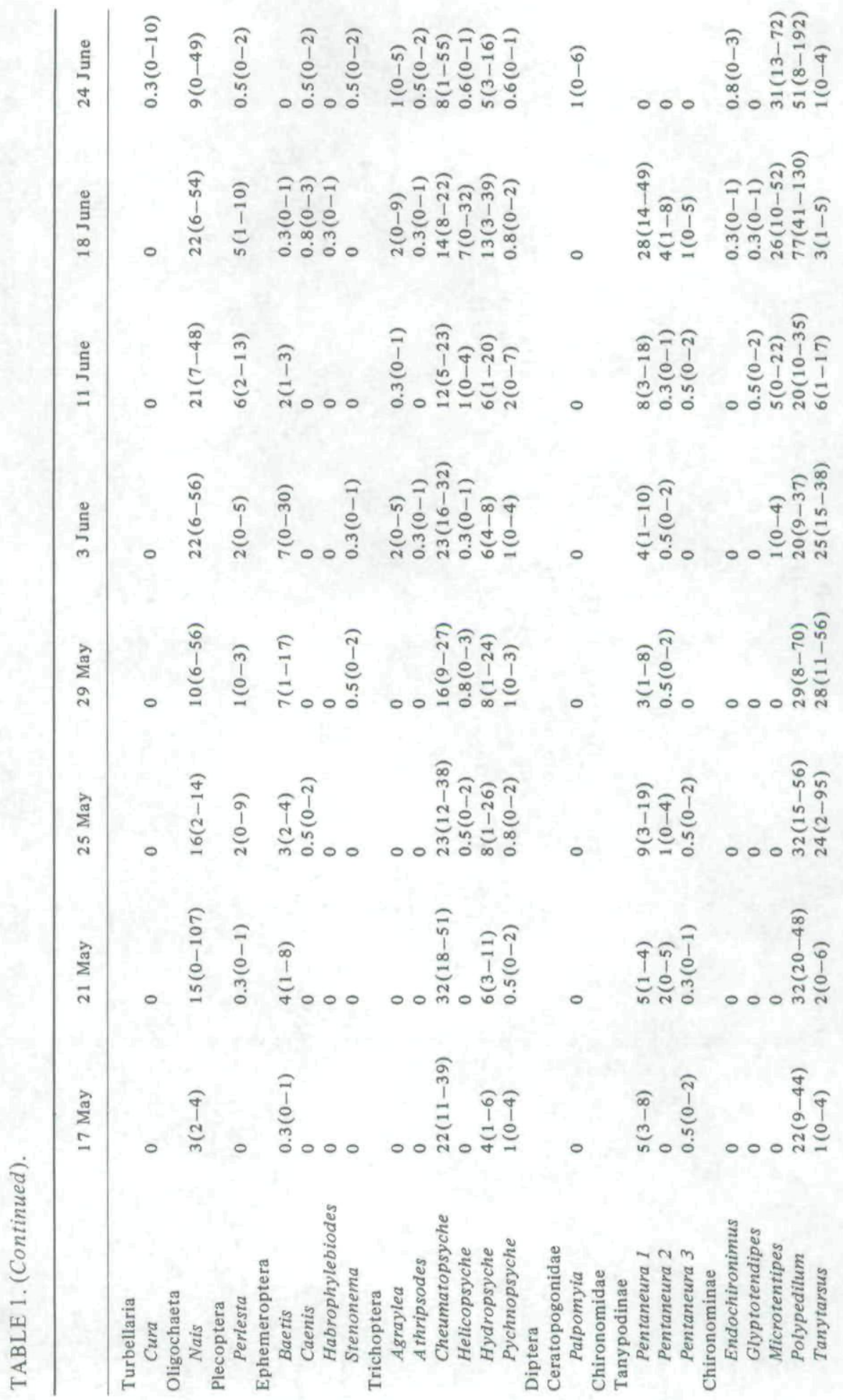




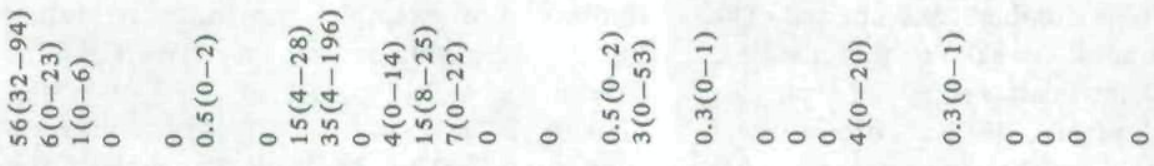

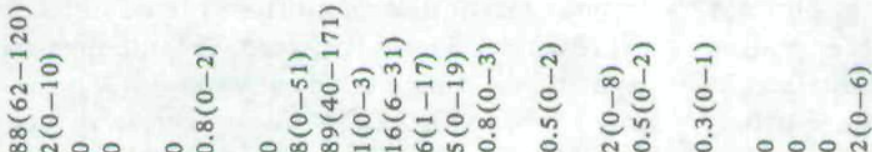

舟

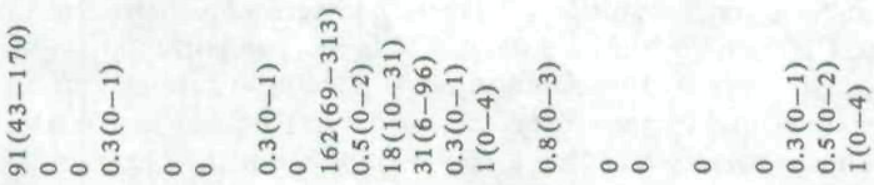

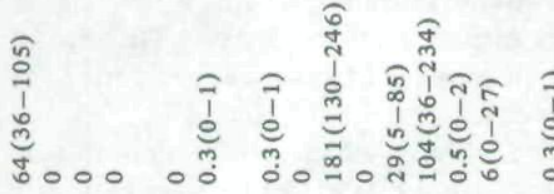

00000

0000000000000

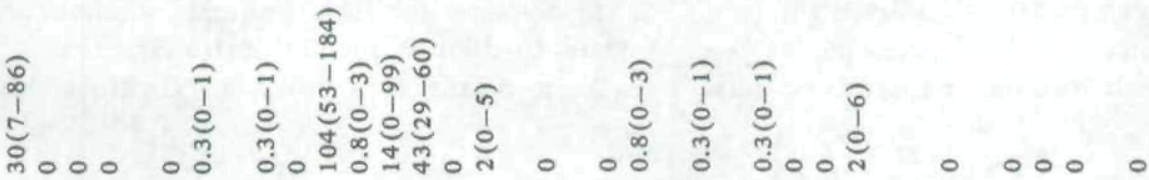

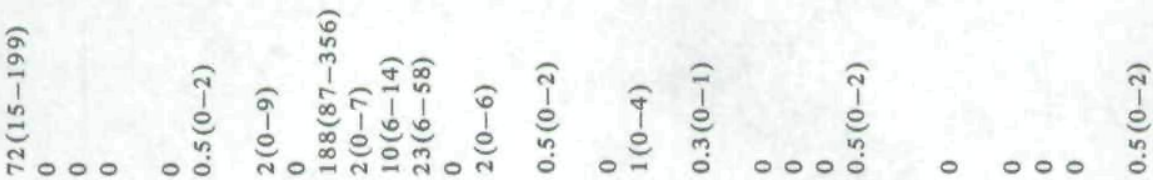

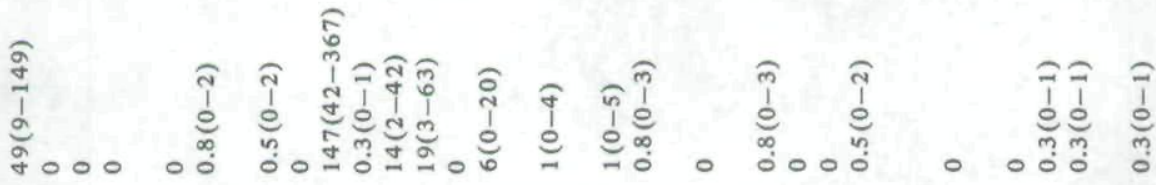

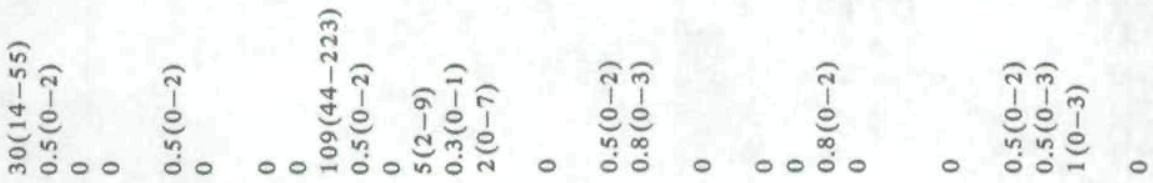

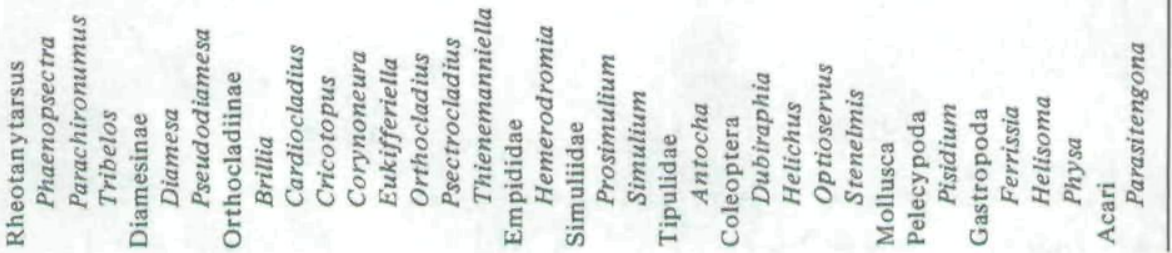


After this period, an apparent decline instead of levelling off in numbers was noticed. The emergence of adult insects is the plausible explanation. The relationship between the stage of development of the various insect species and the length of substrate exposure was not determined. Nevertheless, it was observed that many more of the midges had reached later larval instar stages after 39 days of exposure than after 16 days. Furthermore, larger numbers of chironomid pupae were collected after 39 days. A similar trend was apparent with the Trichoptera. Caddisfly pupae first became evident after 30 days and increased in prevalence. For example, after 47 days, $40 \%$ of the total number were pupae of Cheumatopsyche sp. and Helicopsyche borealis Hagen.

Coefficients of variation $(\mathrm{CV})$ in total numbers of individuals for the four replicate samples retrieved on each particular sampling day fluctuated considerably during the 60-day study. Mason et al. (1973) reported the lack of a trend toward either increasing or decreasing $C V$ with different exposure periods.
The results from this study support their findings. For example, the following values for $C V$ were obtained on successive sampling dates in 1974: 26.6 on 29 April, 5.1 on 1 May, 45.0 on 5 May, 56.0 on 21 May, 28.0 on 3 June, and 15.0 on 18 June. The lack of any trend seems quite evident from these results.

The relationship between the number of taxa and differing periods of exposure was also investigated (Fig. 2). A linear regression line was fitted to the data and was highly significant $(P<0.01)$ with a regression coefficient of $0.31 \pm 0.0595 \%$ CL. It is important to note the absence of any definite leveling off in taxa over the 60 days. This was in contrast to the trend exhibited with mean total number of organisms, where a decline in numbers occurred after 39 days. The rate of increase in number of taxa was determined as 0.31 per day.

One conclusion which can be drawn from these data is that 60 days of sampler exposure is inadequate for the optimal number of species to colonize the multiplate samplers.

As a means of further investigating the

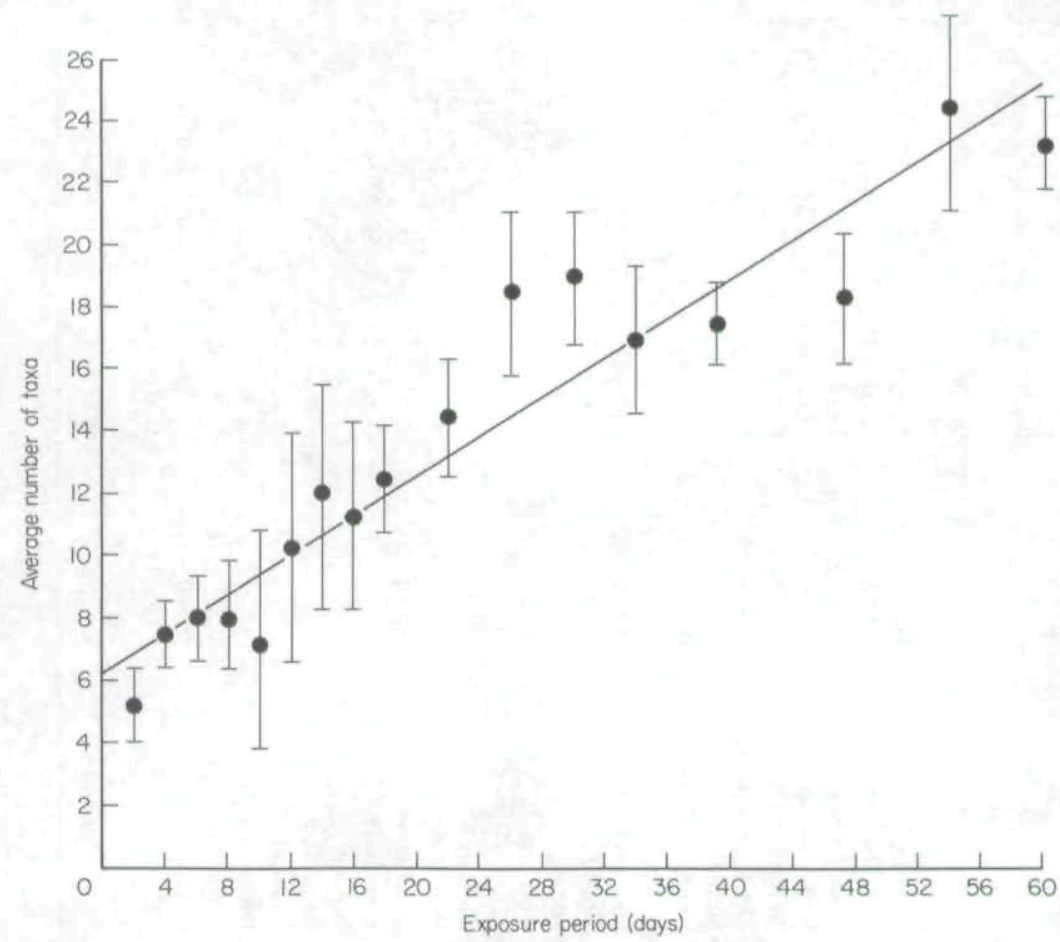

FIG. 2. Rate of accrual taxa for the 60-day study period. The solid line represents a linear regression. Each value is a mean and $95 \%$ confidence in terval. 
possible inadequacy of the recommended 6-week period of exposure, the relationship between changes in diversity and colonization time was examined. Indices of diversity based on information theory, as originally proposed by Margalef (1957), include two components of species diversity: (1) number of species, and (2) distribution of individuals among the species. The Shannon-Weaver equation (Weber, 1973) was utilized for determining mean diversity $(\bar{d})$ :

$\bar{d}=\frac{C}{N}\left(N \log _{10} N-\Sigma n_{i} \log _{10} n_{i}\right)$

where $C=3.32$ (converts base $10 \log$ to base 2), $N=$ total number of individuals, and $n_{i}=$ total number of individuals in the $i$ th species.

Mean diversity was calculated for samples collected in this study to determine the relationship between community diversity and exposure period. A linear relationship between diversity and exposure time was obtained (Fig. 3). The regression line was highly significant $(P<0.01)$ with a regression coefficient of $0.019 \pm 0.00595 \% \mathrm{CL}$. The absence of any obvious levelling off during the course of 60 days was notable. This can be attributed to adult insect emergence and creation of new niches.

The increase of emerging adult insects, indicated by the decrease in numbers of immatures during the latter portion of the study, could have produced a condition where the diversities increased. Such a phenomenon would not be actually related to the influence of increased time of exposure of the multiplate samples, but simply to the natural seasonal emergence of the adult insects. However, this hypothesis falls somewhat short in explaining the continued increase in numbers of species throughout the duration of the study.

It was also shown that the number of taxa increased throughout the course of the study. The possibility that this can be accounted for entirely by the increased chance of colonization of drifting organisms through time seems remote, since one would have expected nearly all of the macro-invertebrate taxa to have been exposed to the samplers sometime prior to the completion of this investigation. This supports the hypothesis that the growth of the 'Bewuchs' community on the samplers enhanced the colonization by new species. The more specialized nature of these taxa could

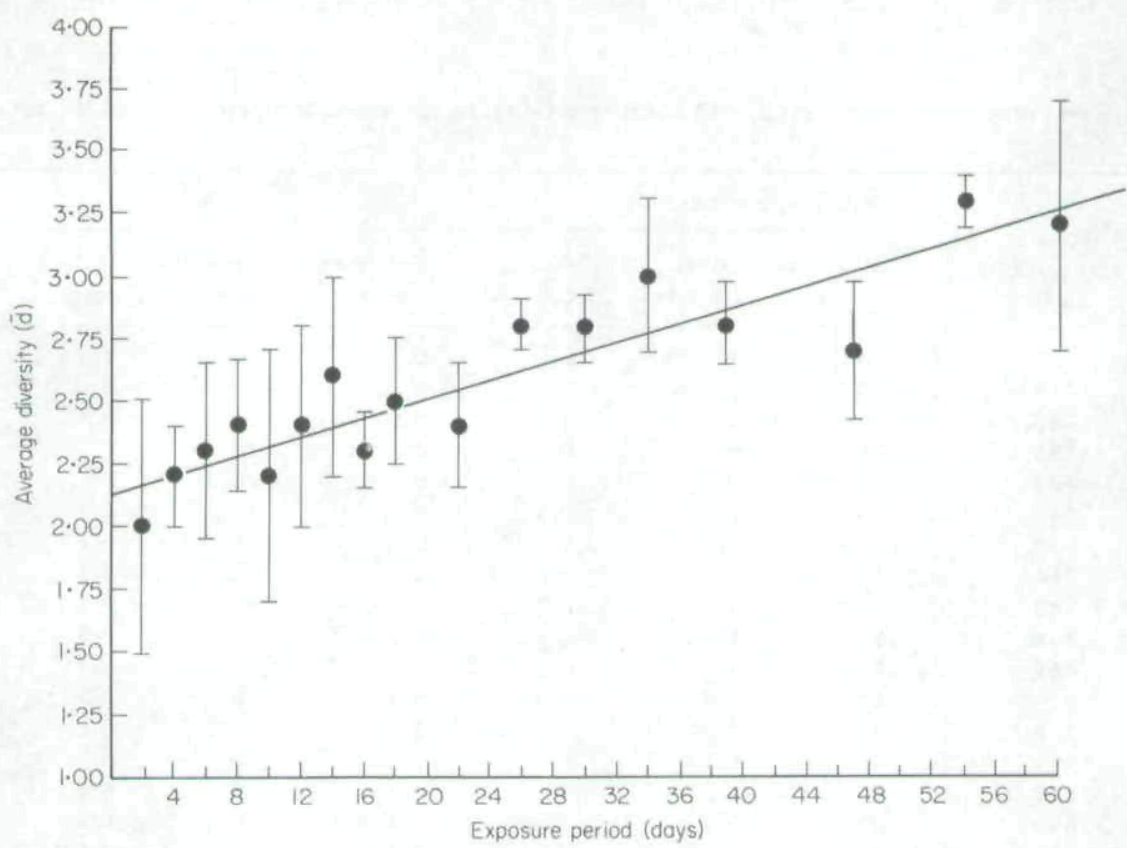

FIG. 3. Changes in average diversity (calculated from equation 1) against times of exposure. 
have given rise to certain competitive advantages which resulted in a partial crowding out of the established organisms.

The macro-invertebrates inhabiting the multiplate samplers consisted primarily of insects. At no time did this group make up less than $95 \%$ of the total number of organisms (Table 2). Examination of these data showed that species composition did vary somewhat with length of exposure. The two groups of organisms which made up the bulk of the macro-invertebrates collected were the Chironomidae and Trichoptera, which accounted for over $90 \%$ of the sampled macro-invertebrates on every sampling day exclusive of the first collection. The midges made up a somewhat smaller portion of the total sampled population during the early portion of the study than at a later stage. In contrast, the percentage of caddisflies showed a general decrease throughout the course of the study.

Individual taxa showed much greater fluctuations in numbers than the larger categories (Table 1). For example, the number of Eukiefferiella was extremely low up to the 21 May sampling date and then suddenly increased until it made up a significant portion of the chironomid population. Another member of the Orthocladiinae,
Orthocladius, was not present until 7 May, 1974. After that it increased in numbers until this group made up a substantial portion of the midges.

The sudden increases in the numbers of taxa after previous periods of sparseness supports the suggestion that new niches were created with increasing periods of exposure by the growth of periphyton and the accumulation of detritus on the multiplate samplers. The availability of food may be another factor which affected the macro-invertebrate community, since most of the collected organisms were primarily consumers of algae (Cummins, 1973). Other groups such as the caddisfly Cheumatopsyche and the chironomids Cricotopus, Polypedilum and Rheotanytarsus, were collected in large numbers throughout the study, whereas the mayfly Baetis and the chironomids Orthocladius and Cricotopus showed a decrease on the last two sampling dates.

Wilhm (1970) has reported that where degradation of waters is at low to moderate levels, diversity indices lack the sensitivity to demonstrate slight differences in water quality. The 'equitability' function (Lloyd \& Ghelardi, 1964) on the other hand, was reported as being very sensitive to even slight levels of degradation. Equitability $(E)$ was

TABLE 2. The numbers of various groups of macroinvertebrates, expressed as a percentage of the total number collected

\begin{tabular}{|c|c|c|c|c|c|c|c|c|}
\hline \multirow{2}{*}{ Date } & \multirow{2}{*}{$\begin{array}{l}\text { Total no. of } \\
\text { organisms }\end{array}$} & \multicolumn{7}{|c|}{ Percentage of total } \\
\hline & & $\begin{array}{l}\text { Chirono- } \\
\text { midae }\end{array}$ & $\begin{array}{l}\text { Other } \\
\text { Dipterans }\end{array}$ & $\begin{array}{l}\text { Plecop- } \\
\text { tera }\end{array}$ & $\begin{array}{l}\text { Ephemer- } \\
\text { optera }\end{array}$ & $\begin{array}{l}\text { Trichop- } \\
\text { tera }\end{array}$ & $\begin{array}{l}\text { Coleop- } \\
\text { tera }\end{array}$ & $\begin{array}{l}\text { Non- } \\
\text { insects }\end{array}$ \\
\hline $27 \mathrm{Apr}$ & 78 & 40 & 15 & 0 & 0 & 44 & 1 & 0 \\
\hline $29 \mathrm{Apr}$ & 213 & 70 & 0.5 & 2 & 0 & 27 & 0 & 0.5 \\
\hline 1 May & 283 & 74 & 0.5 & 0 & 0.5 & 24 & 0.5 & 0.5 \\
\hline 3 May & 335 & 78 & 0.5 & 0 & 0 & 20 & 0 & 1.5 \\
\hline 5 May & 302 & 70 & 0 & 0 & 0 & 26 & 0 & 4 \\
\hline 7 May & 340 & 73 & 0.7 & 0.3 & 0 & 24 & 0 & 2 \\
\hline 9 Мay & 690 & 79.4 & 0.4 & 0.1 & 0 & 15 & 0.1 & 5 \\
\hline 11 May & 754 & 87 & 0.9 & 0 & 0 & 9 & 0.1 & 3 \\
\hline 13 May & 583 & 77.5 & 1 & 0.2 & 0 & 17 & 0.3 & 4 \\
\hline 17 May & 836 & 84 & 0.6 & 0 & 0.1 & 13 & 0.3 & 2 \\
\hline 21 May & 1361 & 80.5 & 1 & 0.1 & 1 & 12 & 0.4 & 5 \\
\hline 25 May & 1670 & 86 & 0.4 & 0.5 & 0.8 & 8 & 0.3 & 4 \\
\hline 29 May & 1208 & 85 & 0.2 & 0.2 & 3 & 9 & 0.6 & 3 \\
\hline 3 Jun & 1987 & 87 & 0.1 & 0.4 & 1.4 & 6 & 0.2 & 5 \\
\hline $11 \mathrm{Jun}$ & 1581 & 87 & 0.3 & 2 & 0.3 & 5 & 0.4 & 5 \\
\hline $18 \mathrm{Jun}$ & 1690 & 83 & 0.7 & 1 & 0.3 & 9 & 0.1 & 5 \\
\hline 24 Jun & 935 & 85 & 2 & 0.2 & 0.3 & 7 & 0.5 & 5 \\
\hline
\end{tabular}




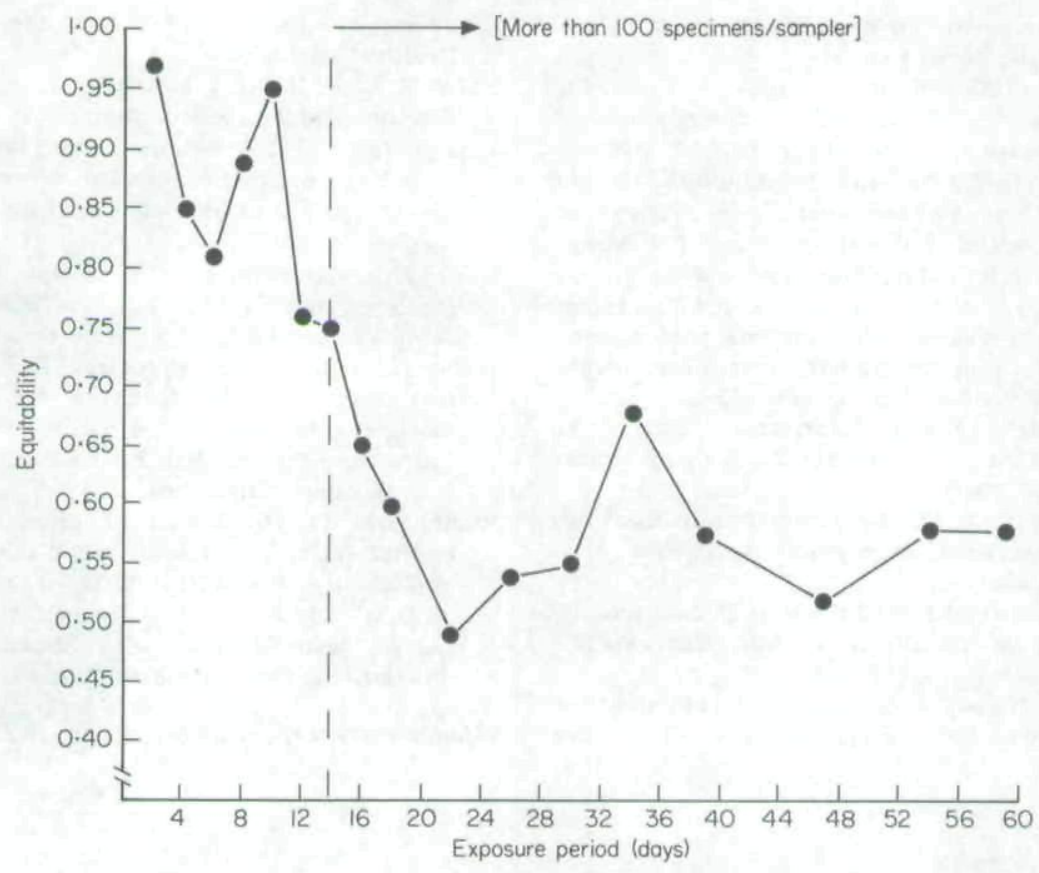

FIG. 4. Variability of mean equitability (calculated from equation 2) against time.

calculated from

$E=\frac{S^{\prime}}{S}$

where $S^{\prime}=$ number of taxa in the sample and $S=$ number of taxa expected (see Lloyd \& Ghelardi, 1964).

Therefore, variations in equitability with different periods of sampler exposure were also investigated in this study. The mean equitability values of the four samples retrieved on each sampling day were determined (Fig. 4). Weber (1973) suggests that samples containing fewer than 100 specimens should be evaluated with caution. Fourteen days of exposure passed before more than a mean of 100 specimens were collected per sampler. The equitability values initially decreased but then levelled off after 24 days of exposure. This is in marked contrast to the diversity index (Fig. 3), which increased with longer periods of sampler exposure. These conflicting results between species diversity and equitability indicate a need for further investigation of equitability as a means of evaluating quantitative data.

\section{References}

Beck W.M., Jr \& Beck E.C. (1966) Chironomidae (Diptera) of Florida I. Pentaneurini (Tanypodinae). Bull. Florida State Mus. 10(8); 305-379.

Brinkhurst R.A. \& Jamieson B.G.M. (1971) Aquatic Oligochaeta of the World. University of Toronto Press, Toronto.

Burks B.D. (1953) The mayflies, or Ephemeropter, of Illinois. Bull. Illinois Nat. Hist. Survey, 26(1).

Cairns J., Jr \& Dickson K.L. (1971) A simple method for the biological assessment of the effects of waste discharges on aquatic bottomdwelling organisms. J. Wat. Poll. Control Fed. 43, 755-771.

Chernovskii A.A. (1949) Identification of Larvae of the Midge Family. U.S.S.R. Academy of Science Press, Moscow.

Cummins K.W. (1973) Trophic relations of aquatic insects. Ann. Rev. Ent. 18, 183-206.

Frison R.H. (1953) The stoneflies, or Plecoptera, of Illinois. Bull. Illinois Nat. Hist. Survey, 20(4).

Hester F.E. \& Dendy J.S. (1962) A multiplate sampler for sampling benthic stream invertebrates. Limn. Oceanogr. 14, 465-471.

Hilsenhoff W.L. (1970) Key to the Genera of Wisconsin Plecoptera Nymphs, Ephemeroptera Nymphs, and Trichoptera Larvae. Resources Report 67, Dept. of Nat. Res., Madison, Wisconsin.

Johannsen O.A. (1937) Aquatic Diptera. Part III. Chironomidae: subfamilies Tanypodinae, 
Diamesinae, and Orthocladiinae. Mem. 205, Cornell Univ. Agric. Exp. Sta.

Lloyd M. \& Ghelardi R.J. (1964) A table for calculating the 'equitability' component of species diversity.J. Anim. Ecol. 33, 217-225.

Mason W.T. Jr (1973) An Introduction to the Identification of Chironomid Larvae, Analytical Quality Control Laboratory, Natural Environment Research Center, Cincinnati.

Mason W.T., Jr, Weber C.I., Lewis P.A. \& Julian E.C. (1973) Factors affecting the performance of basket and multiplate macroinvertebrate samplers. Freshwat. Biol. 3, 409-436.

Margalef D.R. (1957) Information theory in ecology. Gen. Syst. 3, 36-71 (English translation by W. Hall).

Roback S.S. (1957) The Immature Tendipeds of the Philadelphia Area. Monograph Acad. Nat. Sci, No. 9, Philadelphia.

Ross H.H. (1944) The caddisflies, or Trichoptera, of Illinois. Bull. Illinois State Nat. Hist. Survey 23(1).

Sinclair R.M. (1964) Water Quality Requirements of the Family Elmidae (Coleoptera). Tennessee
Stream Pollution Control Board, Dept. of Public Health, Nashville.

Sokal R.R. \& Rohlf F.J. (1969) Biometry, W. H. Freeman and Co., San Francisco.

Usinger R.L. (1956) Aquatic Insects of California, with Keys to North American Genera and California Species. Univ. of California Press, Los Angeles.

Ward H.B. \& Whipple G.L. (1959) Freshwater Biology. 2nd Edition (Ed. W. T. Edmondson). John Wiley and Sons, Inc., New York.

Weber E.I. (Ed.) (1973) Biological Field and Laboratory Methods for Measuring the Quality of Surface Water and Effluents. U.S. Environmental Protection Agency, Nat. Env. Res. Center, Office Res. Develop., Cincinnati.

Wilhm J.L. (1970) Range of diversity index in benthic macroinvertebrate populations. J. Wat. Poll. Control Fed. 42(5), R221-R224.

Wood D.M. (1963) The blackflies of Ontario. Part II. Larval identification with descriptions and illustrations. Proc, Ent. Soc. Ont. 93, 99-129.

(Manuscript accepted 29 September 1978) 
This document is a scanned copy of a printed document. No warranty is given about the accuracy of the copy. Users should refer to the original published version of the material. 